\title{
The Application of Undergraduates' Deep Learning Strategy on Network
}

\author{
Fei Xie ${ }^{1, a^{*}}$, Chao Qin ${ }^{1, b}$ and Zongjie Xiao ${ }^{1, a}$ \\ ${ }^{1}$ School of Education, Yunnan Minzu University, Kunming, China \\ atofiona@163.com, ${ }^{b} 5172658 @ q q . c o m$
}

\section{Keywords: Undergraduate; Deep learning; Network-based learning; Learning strategy}

\begin{abstract}
Network-based learning is an important learning style for undergraduates. Previous studies have carried out many questionnaire surveys and comparative studies on undergraduates' network-based learning strategy. By interviewing undergraduates with different professional backgrounds, this study will conduct deep observation from the perspective of the individual, to understand how undergraduates invoke learning strategies during network learning. The research results have showed that learners can basically complete shallow level in multiple dimensions and expand some deep level learning, but the degree of deep learning needs to be improved.
\end{abstract}

\section{Introduction}

Network technology plays an important role in undergraduates' learning. The $32^{\text {nd }}$ China Internet Development Report shows, students are the largest occupational group of netizen, accounting for $25.5 \%$ [1] It is generally believed that, network-based learning is based on computer network. Due to the characteristics of network, it makes learning more opening, richer resource and more independent. However, the utilization of network resources in undergraduates' learning will not process deeply cognition as expected.

Deep-learning is not only an active, critical learning style but an effective way to achieve meaningful learning. Deep-learning and shallow learning have obvious differences in remembering methods, knowledge hierarchy, focus of attention, learning motivation, learning involvement load, introspection status in learning, thinking level and migration ability of learning outcome etc.[2] According to classification of learning objectives in cognition field proposed by Broome,[3] the cognitive level of shallow learning only stay in knowing and understanding, mainly simple description, memory, or copy of knowledge; but the cognitive level of deepness learning can correspond with application, analysis, synthesis and evaluation. The characteristics of deepness learning are mainly manifested in 4 aspects: comprehension and criticism, knowledge construction, migration and application, and problem solving [4]

However, in practical learning, whether undergraduates can consciously use deep-learning strategies for network-based learning is not determinate. Although undergraduates almost spend numerous time on the Internet every day, in addition to entertainment, they may just download and copy data to complete the work or the task assigned by teacher. Sometimes they have no idea how to choose, analyze and sort huge data on the net; just browse at will. This shallow learning not only takes numerous time and energy for the students, but with little effect.

There are already related researches discussing on this problem. Some studies have investigated the current situation of undergraduates' network-based learning, and described the general situation, as well as explored various performance and characteristics of network-based learning behavior [5][6][7] Some scholars explore the forming and influence of network-based learning type from external and internal factors.[8][9][10] The research on network-based learning strategy is also a hot topic. Some researches summarize the common strategies of undergraduates' network-based learning, and discuss their usage.[11][12][13] Some scholars have put forward theoretical model for the influence of strategy on learning depth degree in network-based learning.[1] In application, some studies point out that network technology is only external mean while enhancing the enthusiasm of students' learning attitude is the key reason to deepen learning degree.[2] To further concern how undergraduates invoke learning strategies during network-based learning, and deeply observing from individual perspective, this paper chooses typical undergraduates to interview and 
discuss.

\section{Methodology}

Instrument. For comprehending the learning process, interview as the research method is used to discuss deepness network-based learning strategy. The interview outline is based on the "S-F-T" three-dimensional model [3] of network-based learning behavior. The model divides network-based learning behavior into three dimensions including structure, function and manner. The network-based learning behavior in structure dimension has four categories from low-level to high-level, respectively operation behavior (explicit operating behavior directly related to learning), cognitive behavior (learners' individual cognitive behavior), collaborative behavior (collaborative communication behavior among different individuals) and the problem solving behavior (the behavior of solving problem, generating answers or solutions). Each level includes some typical behavior set. The function dimension is classification of network-based learning behavior according to information operation, including information query, information organization and processing as well as information release. The manner dimension refers to interactive way, divided into person person interaction and human - machine interaction. According to this model designed interview outline, the main frame is shown as following Table.

Table 1 The interview points

\begin{tabular}{|c|c|c|}
\hline dimension & questions & focus \\
\hline \multirow[t]{5}{*}{ Structure } & Learning task & $\begin{array}{l}\text { Learning aim } \\
\text { Learning content }\end{array}$ \\
\hline & $\begin{array}{l}\text { The application of multi-media } \\
\text { resources }\end{array}$ & $\begin{array}{l}\text { Which multi-media resources } \\
\text { How to obtain and use the multi-media resources } \\
\text { Preference on the usage of multi-media resources }\end{array}$ \\
\hline & $\begin{array}{l}\text { Self-supervision and } \\
\text { self-assessment }\end{array}$ & $\begin{array}{l}\text { How to reject the disturbance } \\
\text { How to evaluate the procession and achievement }\end{array}$ \\
\hline & Difficulty and trouble & $\begin{array}{l}\text { The mental and emotional changes in learning } \\
\text { How to try to solve the difficulties }\end{array}$ \\
\hline & Deficiency and improvement & $\begin{array}{l}\text { Summarize the deficiency of learning strategy } \\
\text { How to improve and promote the learning }\end{array}$ \\
\hline function & $\begin{array}{l}\text { Organization and procession the } \\
\text { information }\end{array}$ & $\begin{array}{l}\text { Learning specifics: do or undo } \\
\text { Time distribution } \\
\text { The mode and degree of network-based learning }\end{array}$ \\
\hline manner & Interaction between the learners & $\begin{array}{l}\text { Interaction specifics } \\
\text { Context of interaction } \\
\text { Preference of interaction } \\
\text { Initiative or passivity }\end{array}$ \\
\hline
\end{tabular}

Participants. Considering different field of learners have different utilization degree of network resources, the common professions have been classified by Delphi method. According to the relationship between profession and computer network learning, it is divided into close, medium, non-close which are coded as A, B and C. Considering the availability, 2 undergraduates of each profession, 6 interview object in total are selected. They are coded as A1, A2, B1, B2, C1 and C2 according to the characteristics of profession background.

\section{Results and Discussion}

Structural Dimension. The Main Task Type in Network-Based Learning. Five students show that they would often carry out network-based learning and the main learning objectives are improving their professions learning. The content is learning software related to profession, then combine theoretical knowledge in class and actual operation skill together. But B2 indicates that he does not 
often carry out network-based learning, the main learning objective is to join postgraduate entrance examination. It can be seen that most students will learn on network but learning motivation is mainly external requirements, such as teachers, examinations, etc.

Usage Type of Multimedia Resources. The video resources with picture, sound, and text are appreciated by 4 students while the other 2 students like the text resources. It is found that learner's media usage is relatively single, just focus on the video, or just focus on the text. The application of school electronic library resources is very little. Few of students are disgusted with the school timing network learning platform.

Self-Assessment and Self-Supervision of Learning. Four students indicate that they have certain plans and stipulate themselves in a certain amount of time to complete learning task. The other two interviewees show that they are more likely to be affected during learning process, if there are games or shopping-on-net in learning midway, then just follow inclinations to play. This explains that learner's self-supervision ability need to be improved, in order to effectively avoid the phenomenon of learning distractions, without random searching in the web. For self-assessment, learners express a sense of achievement after finishing a task, and sometimes give self encouragement; more evaluation methods rely on the teachers.

The Factors Affecting Network-Based Learning Process. In previous issues, it is quite hard to find out the influence on network-based learning from profession background. But an interviewees express that, there are numerous difficulties, such as: learning software is too fast, and some steps will be omitted; online resources are too much to find the right things. B1 expresses that, during searching, he/she will meet some strange data and nouns which need checking again. Sometimes he/she need reworking due to computer crash and not saved data. The other three students express that they seldom encounter difficulties except a small number of technical problems. It indicates the frequency of network-based learning will affect the quantity of difficulties, students learning more on network will encounter more problems, and vice versa. The problems confronting $\mathrm{C}$ students are mostly technical problems, while the difficulties from A students are mainly the choice of learning resources and the optimization. The technical difficulties are mainly to find solution on the Internet, or consult classmates and teachers; the emotional difficulties mainly get overcome through organizing the thought.

Shortage and Improvement in Network-Based Learning. A1 expresses the deficiency in learning is lack of patience, a rush for quick results finally cause unskilled learning; lack of preparation, objects and willpower in learning process; learning approaches are sometimes too rigid. They hope to overcome shortcomings through clear goal, preparing in advance, overcoming anxiety and irritability, flexibly applying network. Other students think the initiative is insufficient, self-supervision is not enough, the technology is not good enough, hope to be more active in near future, master more network learning skills and computer skills. In general, network learning requires a strong self - supervision. The interview shows that the learners believe network-based learning requires special skills, which should be paid attention to in network learning. Since student's network-based learning can only utilize some spare extracurricular time, sometimes all kinds of unexpected examinations will encounter, as well as school's literature and art activities, etc., so the network-based learning time is in disorder, not fixed.

\section{Function Dimension}

Information Querying. Four interviewees express that they use Baidu search engine in learning process because Baidu is convenient with very comprehensive information and familiar for them. One interviewee use other search engine in order to search lots of new things. Another interviewee indicates he/she likes to use Google to find information abroad. For the problem unable to solve, six students express that they will use "Baidu Knows", "Sina Ishare" or some professional forums. A student also expresses he/she would learn in network school, such as the open class of MIT, Stanford University, Yale University and the University of Oxford. Learners of the interviewees can obtain information needed according to their habits or the way they like. Although the profession, learning style, learning experience are different, they have reached the same effect to obtain useful 
things.

Information Organization and Processing. Information organization and processing strategies are mainly following aspects. First, imitation. For example, a liberal arts major students mainly use audio and video data on the net to learn to sing the Lisu minority songs, and repeat the pronunciation of Lisu minority language. Second, fast reading. A student expresses that fast reading in the network is a very proud ability for himself, because he/she can see numerous historical anecdotes and stories in a short period, and timely select valuable things. Third, drawing (but the drawing tool does not necessarily by information technology). For example, a student can draw his own idea into graph, and link data together with logic, similar to the flow chart, thinking map, concept map. Fourth, practice. Two surveyed students indicate that applying skills learned online into their own computer to carry out actual operation is relatively good learning methods.

Information Publish. Interviewees express information publish on the network gets many methods. It can be e-mail, QQ, forum, WeChat, micro-blog, blog, etc. It can be sharing resources to others by face-to-face explanation without network. There will be very frequent information publish in the information processing, and the interviewee roles often change in this process for they can sharing information with others and also get their information at the same time.

\section{Manner Dimension}

For person - person interaction, $\mathrm{C} 1$ and $\mathrm{C} 2$ express they will exchange with classmates in QQ, micro-blog, WeChat. They hope that others can comment on their learning, whether it is about knowledge content or learning experience. B1 and B2 will also interact with classmates in network-based learning, but generally only share information, do not express their views, and the interaction scope is limited within the class or group. Interviewees with the profession close to IT express that in the interaction, what classmates talk about is mostly not related to professional knowledge and sometimes is just aimless chat. But everyone reflects too little communication with teachers. Although all learners are in the interaction, the effect need improve a lot. It should be based on learning tasks to strengthen initiative. Actively elaborating their ideas and maintaining attention in the interaction should be propose.

For man - machine interaction, most interviewees can effectively dialogue with computer, but C1, $\mathrm{C} 2$ express that due to the influence of technical factors, they can't input what they want to express into the device so unable to get effective information.

\section{Integral Analysis}

General speaking, the network learners in this interview have clear learning motivation. Many students will choose their interesting content. Although the students learn online and collaborative discussion, the effect is not good enough mainly caused by the following reasons: the period of simultaneous online is rare; there is no recognized mentor and group leader. Video and text are relatively preferred multimedia resources by students, but resources are still quite limited. When learners encounter difficulties they can connect teachers through the network, but the students lack initiative. in the forum, learners' passive participation is more than initiative sharing, the concerned content is not strongly correlated with learning. Type A students will take great advantage in technology, technical factor is still an important reason causing undergraduates' misery in network-based learning. Generally speaking, undergraduates have basic satisfaction on network-based learning.

Focusing on the perspective of deepness, students in this interview can achieve more than simple copy and remembering information but critically handling knowledge. They can link learned knowledge and other disciplines together. Based on existing knowledge, construct new knowledge, but lack "draw inferences" ability to solve the problem. Learning initiative is not enough. Although learners' learning is not a shallow learning, it hasn't reached the extent of deep learning completely.

\section{Conclusions}


Undergraduates indeed use more resources from network in learning. Technology can definitely bring convenience and conditions for shallow and deep learning. While using network resources, many students also only stay in the shallow level. The use of deep level learning strategies also occurs at times but the frequency is not high enough. Technology simply provides environment and convenience, but learning motivation and attitude are the main reasons for students to develop deep network-based learning. Network resources is expected playing an important role in university learning to promoting the deepness and breadth of student's learning. Students should construct and understand what learning strategies are the most suitable for their own, and what learning strategies can learn more efficiently, making active, efficient and deep network learning become a habit.

\section{References}

[1] CNNIC. 32nd China Internet Development Report.2014-03-09. from: http://it.sohu.com/20140116/n393643304.shtml.

[2] ZHANG H. (2012). The Connotation and the Theoretical Basics of Cognition. China Educational Technology, 309:7-11.

[3] Lorin, W. Anderson, (2009) A Taxonomy for Learning, Teaching and Assessing: A Revision of Bloom's Taxonomy of Educational Objective. Foreign language Teaching and Research Press.

[4] WANG L., TAN Y. (2009), Blog- based Deep Learning: A Case Study of Suzhou Education Blog, Distance Education in China, 12. 41-45.

[5] XU H. (2005). A Survey of the Network-based learning Strategy of College Students. E-education Research, 6.61-63+73.

[6] GAO D. (2008). Investigation and Research on Students' Network Learning Behavior. Central China Normal University.

[7] CHAI Y. (2011). A Survey on College Students' Informal Learning in Web 2.0. E-education Research, 12. 63-68.

[8] ZHANG X.(2008). Relationship Between Network-based learning Behavior and Personality Characteristics of College Students. Northwest Medical Education, 5: 847-848+852.

[9] LI J. (2010). The Experimental Study on the Effects of State Meta-Cognition on Cognitive Load in Network-based learning, Modern Distance Education Research,2, 75-78.

[10]ZHANG J.H., ZHANG J.P. (2009). The Influence Factors and the LICE Model of Network-based learning. E-education Research. 6:73-77.

[11]HU.W., LI F., HE M. (2008). The Structure and the Developing Characteristic of Network-based learning Strategy of College Students. China Educational Technology, 1, 41-44.

[12]ZHANG G. (2009). An Experimentation for the Development of Network-based learning Strategy of College Students. E-education Research. 1. 66-69.

[13]WANG X. (2009). The Study and the Application of Network-based learning Strategy. Central China Normal University.

[14]PENG W. (2012). Analysis and Modeling of Network-based learning Behavior. Central China Normal University.

[15]XIE F.,RAO Y., HUANG C. (2014). A Study of Shallow Procession of On-line Resources in College Students' Network-based learning. Software Guide (Educational Technology), 11. 40-42.

[16]PENG W. (2012). Analysis and Modeling of Network-based learning Behavior. Central China Normal University. 